\title{
Comparison of Postoperative and Oncologic Outcomes in Laparoscopic and Open Right Colectomy for Colon Cancer: A 5-year Experience
}

\author{
EFFROSYNI STAVROU ${ }^{1}$, NIKOLAOS TZANAKIS ${ }^{1}$, ELEFTHERIOS SPARTALIS ${ }^{2}$, \\ DIMITRIOS PATSOURAS ${ }^{2}$, KONSTANTINOS GEORGIOU ${ }^{2}$, \\ GEORGIOS TSOUROUFLIS ${ }^{2}$, DIMITRIOS DIMITROULIS ${ }^{2}$ and NIKOLAOS NIKITEAS ${ }^{2}$ \\ ${ }^{1} 2^{\text {nd }}$ Department of Surgery Asklepieion General Hospital of Voula, Athens, Greece; \\ ${ }^{2} 2^{\text {nd }}$ Department of Propaedeutic Surgery, Medical School of Athens University, Laiko General Hospital, Athens, Greece
}

\begin{abstract}
Background/Aim: Laparoscopic colectomy is a procedure which is being performed for three decades and is gaining popularity continuously over the traditional open colectomy. This study was conducted in order to compare postoperative and oncologic results based on several factors in laparoscopic and open right colectomy for right colon cancer. Patients and Methods: This is a retrospective study of right colectomy at a single institution from 2015 until 2020. The factors that were studied included postoperative values of $C$-reactive protein $(C R P)$, lactate dehydrogenase $(L D H)$, creatine phosphokinase $(C P K)$, the number of excised lymph nodes, the use of postoperative analgesics and the length of hospital stay. Results: We collected data from 21 open and 17 laparoscopic right colectomies through a 5-year period. Measurements on the second postoperative day revealed mean $C R P$ and CPK values significantly lower in the laparoscopic group compared to the open group, while LDH levels did not affirm major differences between the two groups. The mean number of lymph nodes excised during the open procedure was superior to those harvested in the laparoscopic group. The use of analgesics throughout the entire hospital stay was a combination of pethidine and tramadol for the first three postoperative days in open procedures, while paracetamol and, occasionally, tramadol were administered upon patient request following laparoscopic procedures. The mean hospital stay was
\end{abstract}

This article is freely accessible online.

Correspondence to: Effrosyni Stavrou, $2^{\text {nd }}$ Department of Surgery Asklepieion General Hospital of Voula Vasileos Pavlou 1, 16673, Athens, Greece. Tel: +30 2132163000, +30 6940565542, Fax: +30 2132163027, e-mail: sissystavrou@gmail.com

Key Words: Laparoscopic right colectomy, right colon cancer, postoperative values, lymph node excision. substantially shorter in the laparoscopic group compared to the open surgery group. Conclusion: Laparoscopic right colectomy is superior compared to open right colectomy with regards to postoperative analgesia and length of hospital stay, but also in certain postoperative laboratory values. Despite these there was no supremacy considering oncologic clearance.

Colorectal cancer is the most common malignancy in the Western World and the second cause of death (1). Right-sided colon cancer represents one third of all cases and is traditionally treated by right hemicolectomy (2). Laparoscopic colorectal surgery was first described by Jacobs et al. (3) in 1991 and is widely accepted for the treatment of both benign and malignant left colon and rectal pathologies (4). Laparoscopic approach in the right colon still remains controversial, probably due to the complexity of right colon laparoscopic anatomy and the vulnerability of the vascular peduncles that require a greater attention and laparoscopic experience compared to left colon and rectal surgery (5).

The purpose of this study was to compare the postoperative and oncological results after laparoscopic and open right colectomy for right-sided adenocarcinoma, and decipher the advantages of the laparoscopic technique over the conventional open one.

\section{Patients and Methods}

Patients. We carried out a retrospective analysis of patients with right sided colonic adenocarcinoma who underwent either open, or laparoscopic right colectomy in a single institution during a 5-year period, from January 2015 until June 2020.

Several patients were excluded from the study, such as those who were i) immunocompromised, ii) with distant metastases, iii) with lesions other than colonic adenocarcinoma, iv) with acute complications, such as obstruction, or rupture, requiring an emergency operation, and v) cases in which laparoscopy was converted into laparotomy. 
Table I. Demographic data and comorbidities of patients.

\begin{tabular}{lccccccc}
\hline & No of patients & Type II diabetes & AFib & DLP & HTN & Age (mean in years) & BMI (mean in kg/m²) \\
\hline Males & 23 & 16 & 3 & 17 & 11 & $60.1 \pm 15.2$ & $24.6 \pm 6.3$ \\
Females & 15 & 10 & 4 & 12 & 8 & $67.5 \pm 13.4$ & $27.9 \pm 7.8$ \\
\hline
\end{tabular}

AFib: Atrial fibrillation; DLP: dyslipidemia; HTN: hypertension; BMI: body mass index.

Our study encompassed 38 patients, 17 of whom belonged to the laparoscopic group and 21 to the open group (Table I).

Preoperative procedures. All patients had preoperative colonoscopy with removal of biopsies to confirm the presence, exact location and type of the tumour, while the marking of the tumour with methylene blue was only performed in patients who would undergo a laparoscopic procedure. All patients underwent abdominal ultrasonography and CT examination of the abdomen and thorax as well as standard laboratory tests, such as complete blood count, tumour markers (carcinoembryonic antigen, CA 19-9), thyroid hormones, and basic biochemical values (urea, creatinine, $\mathrm{Na}+, \mathrm{K}+$, blood glucose). Bowel preparation was achieved using disodium phosphate dodecahydrate and preoperative broad-spectrum antibiotics were initiated $24 \mathrm{~h}$ before the operation.

Open and laparoscopic surgical procedures. In both groups, a Foley catheter and a nasogastric tube were routinely used, which were inserted following the induction of general anaesthesia at the operating theatre.

Patients undergoing right laparoscopic colectomy were placed in lithotomy position. Pneumoperitoneum was achieved using a Verres needle inserted to the left hypochondrium and the abdomen was insufflated to $12 \mathrm{~mm} \mathrm{Hg}$. The $12 \mathrm{~mm}$ trocar was placed supraumbilically and a $10 \mathrm{~mm}$ one was placed at the left hypochondrium, at the site of the Verres needle insertion. Another two $5 \mathrm{~mm}$ trocars were placed in the lower abdomen, one $2-3 \mathrm{~cm}$ anteriorly and medially to the anterior superior iliac spine on the left side and one in the right lower abdomen on the right side. After the port placement, the patients were tilted 20 degrees to the left and in slight Trendelenburg position. In all operations the terminal ileum, cecum, and ascending colon were completely mobilized up to the level of hepatic flexure, with particular attention to safeguard the ureter and the duodenum in a medial to lateral approach. Ileocolic, right colic and the right branch of the middle colic vessels were ligated with endoscopic clips and with the use of bipolar cautery. The anastomosis was in all cases extracorporeal laterolateral ileotransverse as well as isoperistaltic, by extending the supraumbilical incision to about $6-7 \mathrm{~cm}$.

The open group underwent typical right hemicolectomy with midline incision and medial to lateral colon mobilization. The anastomosis was laterolateral ileotransverse, same as in the laparoscopic group, but it was made either iso- or antiperistaltic, depending on the surgeon's preference. The midline incision was closed in layers using a separate popropylene suture for each layer.

A penrose drain was placed in all patients, in the rectouterine space in females and in the rectovesical space in males, regardless of the type of operation.

Postoperative procedures. The following parameters (Table II) were measured prospectively: i) C-reactive protein (CRP), ii) creatine
Table II. All the parameters studied during the operation and postoperatively. Values are expressed as mean \pm standard deviation. $* p>0.05, * * p>0.005$.

\begin{tabular}{lccl}
\hline & $\begin{array}{c}\text { Laparoscopic } \\
\text { group }\end{array}$ & $\begin{array}{c}\text { Open } \\
\text { group }\end{array}$ & $p$-Value \\
\hline CRP & $102.23 \pm 36.55$ & $132.14 \pm 24.80$ & $0.0049 * *$ \\
CPK & $162.76 \pm 10.17$ & $470.42 \pm 51.52$ & $0.0208^{*}$ \\
LDH & $184.82 \pm 47.20$ & $222.80 \pm 68.18$ & 0.0593 \\
No of lymph nodes & $19.52 \pm 6.49$ & $27.95 \pm 9.47$ & $0.0035^{* *}$ \\
Days of hospital stay & $5.76 \pm 0.93$ & $8.80 \pm 3.41$ & $0.0011^{* *}$ \\
\hline
\end{tabular}

CRP: C-reactive protein; CPK: creatine phosphokinase; LDH: lactate dehydrogenase.

phosphokinase (CPK) and iii) lactate dehydrogenase (LDH), all on the second postoperative day, iv) the number of lymph nodes harvested, v) analgesic requirements and vi) the duration of hospital stay.

Statistics. All our data are expressed as mean \pm SD and Unpaired $t$-test through GraphPad software was used to analyze several quantitative variables. We considered $p<0.05$ as statistically significant.

\section{Results}

The patients that were included in our study were all diagnosed with a right-sided colon adenocarcinoma with similar demographic data and comorbidities (Table I).

On the second postoperative day all patients were tested for LDH, CRP and CPK. There was no significant difference between the open and the laparoscopic group regarding the postoperative levels of LDH; our measurements revealed a mean LDH level of 222.80 in open and 184.82 in laparoscopic group $(p=0.0593)$. The values of postoperative CRP and CPK were considerably lower in the laparoscopic group compared to those of the open surgery group, which, as is widely accepted, are significant predictors of postoperative survival, complications and mortality $(6,7)$. We measured a mean CRP value of 132.14 in open and 102.23 in laparoscopic surgery $(p=0.0049)$, as well as a mean value of CPK levels of 470.42 in open and 162.76 in laparoscopic surgery, respectively $(p=0.0208)$.

The number of excised lymph nodes showed that patients who underwent open right colectomy had superior oncologic clearance, with a mean number of lymph nodes excised 27.95 
compared to those who underwent laparoscopic surgery who had a mean number of lymph nodes equal to $19.52(p=0.0035)$, which shows great significance. In one patient from the laparoscopic group only 10 lymph nodes were harvested, even though the accepted number of lymph nodes during oncologic operations is 12 , according to international literature (8).

The length of postoperative hospital stay was undoubtedly shorter in the laparoscopic group (mean $\pm \mathrm{SD}=5.76 \pm 0.93$ days), when compared to the open group (mean $\pm \mathrm{SD}=8.80 \pm 341$ days) $(p=0.0011)$.

Analgesics were used as a combination of tramadol and pethidine in patients after open surgery for the first three postoperative days, subsequently reducing the use of pethidine and replacing it with paracetamol. Patients in the laparoscopic group were provided with paracetamol for the first three postoperative days and tramadol only upon patient request.

\section{Discussion}

The first successful laparoscopic colectomy was reported by Jacob et al. in 1991 (3) and since then there has been a tremendous development of laparoscopic colonic surgery, especially during the past decade (9). The laparoscope itself is undoubtedly a tool to i) explore thoroughly the abdominal cavity, ii) exclude liver and peritoneal metastases, and iii) prove useful in mobilization and resection of select lesions.

Laparoscopic right colectomy has many technical difficulties and a steep learning curve for the surgeon in order to achieve advanced laparoscopic skills. It also requires specialized equipment and a high number of similar cases designated to the surgeons so as for them to attain familiarity with the specific instruments and for the entire therapeutic team to learn how to cooperate efficiently during this procedure (10). The risk of dissemination and port site metastases from laparoscopic colon surgery have markedly decreased since they were first reported in 1993 (11). Although the mechanism of port-site recurrence is not completely clear yet, and was first noted in thoracoscopic surgery without $\mathrm{CO}_{2}$ insufflation, it is probably caused by a combination of the following factors: i) tumor manipulation, ii) failure to isolate the tumor, and iii) forceful extraction of the surgical specimen (12).

There are only a few publications which specifically compare the outcomes of patients who underwent laparoscopic right hemicolectomy for colon cancer with those who were treated with the open approach (13). Our study confirms that the laparoscopic approach is superior to open surgery regarding the length of hospital stay and, thus, the overall costs of hospitalization. The use of narcotics was minimal in the laparoscopic group, also leading to faster recovery, bowel movement and subsequent defecation. Although not included in this study, minimization of postoperative pain due to the length of the incision $(<7 \mathrm{~cm})$ leads to faster patient mobilization, reduction of postoperative respiratory complications, and surgical site infections (SSIs) (14).

Moreover, the levels of CPK and CRP as major indicators of tissue and muscle damage, postoperative tissue inflammation and destruction (6), as well as the predictive value of CRP concerning anastomotic complications (7), provided important parameters for assuring the safe discharge of our patients from the hospital. Importantly, in our study both these factors were found at significantly lower levels following laparoscopic right colectomy compared to the open surgery group. The levels of LDH, which is also an indicator of tissue injury (15) was not significantly lower in the laparoscopic group compared to the open surgery group.

A more extensive nodal resection has been associated with lower rates of cancer recurrence, as it allows for accurate cancer staging and a more appropriate use of adjuvant chemotherapy for node-positive patients. Importantly, it has also been associated with improved survival following resection for colon cancer (16). A resection of minimum 12 nodes has been endorsed as a consensus standard following safe colectomy for colon cancer (17). Lymph node excision in this study and, thus, possibly the oncologic outcomes may still be more advantageous following open surgery compared to laparoscopy, since the number of overall lymph nodes harvested was higher during the former than the latter.

In conclusion, our study concludes that laparoscopic right colectomy is superior to open surgery concerning postoperative analgesia and length of hospital stay, and also with respect to certain postoperative laboratory values, such as CRP and CPK. Unfortunately, laparoscopy remains less efficient when it comes to oncologic clearance.

\section{Conflicts of Interest}

There is no relationship with any industry and no potential financial conflicts of interest relevant to the submitted manuscript.

\section{Authors' Contributions}

SE collected and analyzed the data and wrote this article, TN provided patient information and histological data, SE, PD, GK, TG provided technical support and conceptual advice, DD, NN revised and/or reviewed the manuscript.

\section{Acknowledgements}

The Authors thank especially Dr. Nomikos Alexandros for the interpretation of the histological results as long as all the colleagues and nursing staff in the $2^{\text {nd }}$ Department of Surgery in Asklepieion General Hospital of Voula.

\section{References}

1 Siegel R, Naishadham D and Jemal A: Cancer statistics, 2012. CA Cancer J Clin 62(1): 10-29, 2012. PMID: 22237781. DOI: $10.3322 /$ caac 20138 
2 Lohsiriwat V, Lohsiriwat D, Chinswangwatanakul V, Akaraviputh $\mathrm{T}$ and Lert-Akyamanee N: Comparison of shortterm outcomes between laparoscopically-assisted $v s$. transverseincision open right hemicolectomy for right-sided colon cancer: a retrospective study. World J Surg Oncol 5: 49, 2007. PMID: 17498289. DOI: $10.1186 / 1477-7819-5-49$

3 Jacobs M, Verdeja JC and Goldstein HS: Minimally invasive colon resection (laparoscopic colectomy). Surg Laparosc Endosc 1(3): 144-150, 1991. PMID: 1688289.

4 Künzli BM, Friess H and Shrikhande SV: Is laparoscopic colorectal cancer surgery equal to open surgery? An evidence based perspective. World J Gastrointest Surg 2(4): 101-108, 2010. PMID: 21160858. DOI: 10.4240/wjgs.v2.i4.101

5 Fabozzi M, Cirillo P and Corcione F: Surgical approach to right colon cancer: From open technique to robot. State of art. World J Gastrointest Surg 8(8): 564-573, 2016. PMID: 27648160. DOI: $10.4240 /$ wjgs.v8.i8.564

6 Morimoto M, Honjo S, Sakamoto T, Yagyu T, Uchinaka E, Hanaki T, Watanabe J, Matsunaga T, Yamamoto M, Fukumoto Y, Tokuyasu N and Fujiwara Y: Prognostic Impact of Pre- and Post-operative P-CRP Levels in Pancreatic Cancer Patients. Yonago Acta Med 63(1): 70-78, 2020. PMID: 32158336. DOI: 10.33160/yam.2020.02.011

7 Singh PP, Zeng IS, Srinivasa S, Lemanu DP, Connolly AB and Hill AG: Systematic review and meta-analysis of use of serum C-reactive protein levels to predict anastomotic leak after colorectal surgery. Br J Surg 101(4): 339-346, 2014. PMID: 24311257. DOI: $10.1002 /$ bjs. 9354

8 Renshaw AA and Gould EW: How many lymph nodes are enough in a colorectal resection? Am J Surg Pathol 44(9): 1290-1292, 2020. PMID: 32496435. DOI: 10.1097/PAS .0000000000001504

9 Di Lascia A, Tartaglia N, Petruzzelli F, Pacilli M, Maddalena F, Fersini A, Pavone G, Vovola F and Ambrosi A: Right hemicolectomy: laparoscopic versus robotic approach. Ann Ital Chir 91: 478-485, 2020. PMID: 32543465.

10 Tekkis PP, Senagore AJ, Delaney CP and Fazio VW: Evaluation of the learning curve in laparoscopic colorectal surgery: comparison of right-sided and left-sided resections. Ann Surg 242(1): 83-91, 2005. PMID: 15973105. DOI: 10.1097/01.sla.0000167857. 14690.68
11 Emoto S, Ishigami H, Yamaguchi H, Ishihara S, Sunami E, Kitayama $\mathbf{J}$ and Watanabe T: Port-site metastasis after laparoscopic surgery for gastrointestinal cancer. Surg Today 47(3): 280-283, 2017. PMID: 27226019. DOI: $10.1007 /$ s00595-016-1346-0

12 Mouiel J, Gugenheim J, Toouli J, Crafa F, Cursio R and Chastanet S: Port-site recurrence of cancer associated with laparoscopic diagnosis and resection: the European experience. Semin Laparosc Surg 2(3): 167-175, 1995. PMID: 10401081. DOI: $10.1053 /$ SLAS00200167

13 Athanasiou CD, Markides GA, Kotb A, Jia X, Gonsalves S and Miskovic D: Open compared with laparoscopic complete mesocolic excision with central lymphadenectomy for colon cancer: a systematic review and meta-analysis. Colorectal Dis 18(7): O224O235, 2016. PMID: 27187520. DOI: 10.1111/codi.13385

14 Noorit P, Siribumrungwong B and Thakkinstian A: Clinical prediction score for superficial surgical site infection after appendectomy in adults with complicated appendicitis. World $\mathbf{J}$ Emerg Surg 13: 23, 2018. PMID: 29946346. DOI: 10.1186/s13017018-0186-1

15 So KA, Lee JK, Song JY, Kim JW, Lee NW, Ki KD, Lee JM, Song YJ, Na YJ, Ku CH, Shin JW, Kim CJ and Jung US: Tissue injuries after single-port and multiport laparoscopic gynecologic surgeries: A prospective multicenter study. Exp Ther Med 12(4): 2230-2236, 2016. PMID: 27698717. DOI: 10.3892/etm.2016.3600

16 Wong SL: Lymph node counts and survival rates after resection for colon and rectal cancer. Gastrointest Cancer Res 3(2 Suppl): S33-S35, 2009. PMID: 19461921.

17 Betge J, Harbaum L, Pollheimer MJ, Lindtner RA, Kornprat P, Ebert MP and Langner C: Lymph node retrieval in colorectal cancer: determining factors and prognostic significance. Int $\mathrm{J}$ Colorectal Dis 32(7): 991-998, 2017. PMID: 28210855. DOI: $10.1007 / \mathrm{s} 00384-017-2778-8$

Received December 15, 2021

Revised January 26, 2022

Accepted January 31, 2022 